\title{
Sleep terrors antecedent is common in adolescents with migraine
}

\author{
0 antecedente de terror noturno é frequente em adolescentes com migrânea \\ Libânia Melo Nunes Fialho', Ricardo Silva Pinho', Jaime Lin'1, Thais Soares Cianciarullo Minett², Maria \\ Sylvia de Souza Vitalle ${ }^{3}$, Mauro Fisberg ${ }^{3}$, Mario Fernando Prieto Peres ${ }^{1,4}$, Luiz Celso Pereira Vilanova ${ }^{1}$, \\ Marcelo Rodrigues Masruha?
}

\begin{abstract}
Migraines and sleep terrors (STs) are highly prevalent disorders with striking similarities. The aim of this study was to evaluate the effect of the antecedent of STs by comparing adolescents suffering from migraines with healthy controls in a large consecutive series. Methods: All patients were subjected to a detailed headache questionnaire and were instructed to keep a headache diary during a two-month period. The age range was 10 to 19 years. The diagnosis of STs was defined according to the International Classification of Sleep Disorders. Results: A total of 158 participants were evaluated. Of these participants, 50 suffered from episodic migraines (EMs), 57 had chronic migraines (CMs) and 51 were control subjects (CG). Participants who had a history of STs had significantly more migraines than participants who did not. Conclusions: Migraine is strongly associated with a history of STs in the adolescent population independent of demographics and pain intensity.
\end{abstract}

Key words: night terrors, migraine disorders, headache, adolescent, sleep disorders.

\section{RESUMO}

Migrânea e terror noturno (TN) são transtornos de alta prevalência que compartilham muitas similaridades. O objetivo desse estudo foi avaliar a ocorrência do antecedente de TN, comparando adolescentes com migrânea e adolescentes saudáveis. Métodos: Todos os pacientes foram submetidos a um questionário detalhado sobre sua cefaleia e foram instruídos a preencher um diário durante um período de dois meses. A idade dos sujeitos variou entre 10 e 19 anos. 0 diagnóstico de TN foi definido de acordo com a Classificação Internacional dos Transtornos do Sono. Resultados: Foram avaliados 158 sujeitos. Desses indivíduos, 50 apresentavam migrânea episódica, 57 migrânea crônica e 51 eram controles. Participantes que tinham o antecedente de TN apresentavam significativamente mais crises de migrânea do que aqueles que não tinham. Conclusões: Migrânea esteve fortemente associada ao antecedente de TN na população de adolescentes independentemente de variáveis demográficas e intensidade da dor.

Palavras-Chave: terrores noturnos, transtornos de enxaqueca, cefaleia, adolescentes, transtornos do sono.

Migraine headache is the most common neurological complaint in adolescents ${ }^{1}$. It causes a significant number of missed school days ${ }^{2}$ and is associated with several comorbidities, such as sleep disorders, anxiety and depression ${ }^{3}$.

Sleep terrors (STs) are considered a parasomnia that are characterized by a sudden arousal from slow-wave sleep with a piercing scream or cry accompanied by autonomic and behavioral manifestations of intense fear ${ }^{4}$. The prevalence is approximately $3 \%$ in children and less than $1 \%$ in adults ${ }^{4,5}$.
Typically, STs are observed in children between the ages of 4 and 12 years and, as in sleepwalking, tend to resolve spontaneously during adolescence ${ }^{4}$. On average, this disorder lasts 3.9 years, but it has a tendency to continue for a longer time period in children with a family history of STs ${ }^{6}$.

The correlation between parasomnias and migraines has been described in previous studies, and a common pathophysiologic mechanism that involves the serotonergic system has been suggested ${ }^{7-9}$.

1'Department of Neurology and Neurosurgery, Universidade Federal de São Paulo (UNIFESP), São Paulo SP, Brazil;

${ }^{2}$ Department of Public Health and Primary Care, Cambridge University, Cambridge, UK;

${ }^{3}$ Department of Pediatrics, UNIFESP, São Paulo SP, Brazil;

4 Instituto de Ensino e Pesquisa, Hospital Israelita Albert Einstein, São Paulo SP, Brazil.

Correspondence: Marcelo Rodrigues Masruha; Departamento de Neurologia e Neurocirurgia, Universidade Federal de São Paulo; Rua Botucatu 720; 04023-900

São Paulo SP - Brasil; E-mail:mmasruha@ig.com.br

Conflict of interest: There is no conflict of interest to declare.

Support: This study was sponsored by the Fundação de Amparo à Pesquisa do Estado de São Paulo (FAPESP).

Received 11 February 2012; Received in final form 29 August 2012; Accepted 05 September 2012 
Disorders that share the same pathophysiologic features or have similar associated conditions are possibly comorbid. Interestingly, STs share striking similarities with migraines. Both conditions are highly prevalent and have a pathogenesis that is currently unknown ${ }^{1,10,11}$. These conditions are considered multifactorial with neurobiological, genetic and behavioral aspects. In addition, the same pathophysiologic structures are thought to be involved in both conditions ${ }^{5,12,13}$.

The aim of this study was to evaluate the association of ST history in childhood and development of migraines in adolescence.

\section{METHODS}

We performed a transversal study between August 2010 and August 2011 at the Federal University of São Paulo, Brazil. All participants, ages 10-19 years, were divided into the following three groups: adolescents with episodic migraine (EM), adolescents with chronic migraine (CM) and healthy adolescent controls (CG). Migraine was defined according to the diagnostic criteria of the International Classification of Headache Disorders, Second Edition (ICHD-2) ${ }^{14}$, and CM was defined according to the 2006 appendix criteria ${ }^{15}$.

The CG group did not suffer from migraines or any other primary headache syndrome and was selected from an adolescent population with the same sociodemographic background as the migraine group. The exclusion criteria were chronic diseases, secondary headaches, continuous use of any kind of medication, drug addiction or abusive alcohol use. Potential control subjects were excluded if they suffered from migraines or any other primary headache. All subjects or their guardians provided written consent for the study, which was approved by the Ethics Committee of The Universidade Federal de São Paulo.

All patients underwent a detailed headache questionnaire that was divided into sections for demographic data (probing age, gender, ethnic background and educational level for both the patient and their parents), clinical data (age of headache onset, duration, frequency, pain intensity and the presence or absence of an aura), history and age of onset of STs. In addition, all patients were instructed to keep a headache diary during a two-month period. The diagnosis of ST was defined according to the International Classification of Sleep Disorders ${ }^{4}$.

\section{Data analysis}

The chi-squared ANOVA (one-way analysis of variance) (F) was used when comparing three samples. Significant differences detected with ANOVA were analyzed with Bonferroni's multiple comparisons test to verify which groups differed significantly.

Multiple logistic regression analyses were performed to verify the relationship between STs (as the independent variable) and migraines (as the dependent variable). The dependent variables were analyzed in pairs (CG x EM, CG x CM and EM $\mathrm{x}$ CM). The results are shown as odds ratios (ORs). Mean $( \pm)$ standard deviation values are also reported. A pvalue of less than 0.05 was considered to indicate statistical significance, and all tests were two-tailed. Ninety-five percent confidence intervals (CI) were calculated for the difference between mean values and ORs. All statistical analyses were performed with the Statistical Package for Social Sciences (SPSS) 11.5.1 for Windows.

\section{RESULTS}

A total of 194 subjects were referred for the study. Of these, 36 subjects were excluded for the following reasons: 8 refused to participate, 6 did not give a reliable medical history and 22 had at least one exclusion criteria. The analysis of the remaining 158 subjects is shown below. Of these, 50 had episodic migraine, 57 had chronic migraine and 51 served as the control group.

There were significant differences between the three groups regarding age $(\mathrm{F}(2,155)=10.5, \mathrm{p}<0.001)$, with control subjects being older $(15.4 \pm 1.9$ years $)$ than subjects with episodic migraine (14.1 \pm 2.7 years; $95 \% \mathrm{CI}$ (difference) $0.1-2.5$ ) and chronic migraine (13.2 \pm 2.6 years; 95\%CI (difference) 1.0-3.3). The proportion of women was higher in the chronic migraine group $\left(\mathrm{CM}=45 \%, \mathrm{CG}=29 \%, \mathrm{EM}=26 \% ; \chi^{2}(2)=9.71 ; \mathrm{p}=0.008\right)$.

\section{Clinical characteristics of migraines}

The age of onset for EM patients was $5.5 \pm 2.9$ years, and attack duration had a median of 7.9 hours. For the CM group, age of onset was $5.5 \pm 3.0$ years with a median duration of 7.7 hours. There were no significant differences regarding age of onset $(\mathrm{t}(105)=0.08,95 \% \mathrm{CI}-1.09-1.17 ; \mathrm{p}=0.939)$ or the duration of headache episodes $(t(105)=-0.96$, 95\%CI $-4.75-1.65$, $\mathrm{p}=0.340$ ). The presence of aura was similar in the CM and EM groups (49 vs. $36 \%, \chi^{2}(1)=1.87$; $p=0,171$ ); however, the intensity of pain was significantly higher in the CM than in the EM group (7.1 \pm 1.6 vs. 6.1 \pm 1.9 ; $\mathrm{t}(105)=2.86$; 95\%CI (difference) $-0.3--1.6 ; \mathrm{p}=0.005)$.

\section{Diagnosis of sleep terrors and migraines}

A significantly larger proportion of $\mathrm{CM}$ patients had a history of STs than any of the other patients $(\mathrm{CM}=40 \%, \mathrm{CG}=8 \%$, $\left.\mathrm{EM}=26 \% ; \chi^{2}(2)=15.06 ; \mathrm{p}<0,001\right)$.

Multiple logistic regression analyses were performed to determine if the relationship between STs (as the independent variable) and the development of migraines (as the dependent variable) were independent of age and sex. The dependent variables were analyzed in pairs (CG X EM, CG x CM and EM x CM) (Table).

STs were significantly associated with migraines independent of age and sex. When only considering the CG and 


\begin{tabular}{|c|c|c|c|c|c|c|}
\hline & $\beta$ & SE & Wald $\chi^{2}(1)$ & OR & $95 \% \mathrm{Cl}$ & $p$-value \\
\hline \multicolumn{7}{|l|}{ CGXEM } \\
\hline Age & -0.28 & 0.10 & 8.18 & 0.76 & $0.62-0.92$ & $0.004 *$ \\
\hline Male & -0.27 & 0.46 & 0.36 & 0.76 & $0.31-1.86$ & 0.548 \\
\hline ST & 1.69 & 0.66 & 6.44 & 5.40 & $1.47-19.89$ & $0.011 *$ \\
\hline \multicolumn{7}{|l|}{$\mathrm{CG} \times \mathrm{CM}$} \\
\hline Age & -0.55 & 0.13 & 18.77 & 0.58 & $0.45-0.74$ & $<0.001 *$ \\
\hline Male & -1.89 & 0.63 & 9.09 & 0.15 & $0.04-0.52$ & $0.003 *$ \\
\hline ST & 2.54 & 0.73 & 12.16 & 12.63 & $3.04-52.54$ & $<0.001 *$ \\
\hline \multicolumn{7}{|c|}{$\mathrm{EM} \times \mathrm{CM}$} \\
\hline Age & -0.22 & 0.09 & 6.69 & 0.80 & $0.67-0.95$ & $0.010 *$ \\
\hline Male & -1.66 & 0.49 & 11.33 & 0.19 & $0.07-0.50$ & $0.001 *$ \\
\hline ST & 0.89 & 0.47 & 3.62 & 2.44 & $0.97-6.09$ & 0.057 \\
\hline
\end{tabular}

EM groups, the probability of patients with STs experiencing EM was 5.4 times higher than patients without STs, whereas among CG and CM, the probability of patients with STs suffering from CM was 12.6 times higher than in patients without STs.

\section{DISCUSSION}

The main finding of this study was that migraines are strongly associated with STs in the adolescent population, independent of demographic data and pain intensity. To our knowledge, there are no other studies on this subject that have specifically targeted the adolescent population and compared chronic and episodic migraine patients.

Several previous studies have looked for an association between sleep disorders and headaches in children and adolescents ${ }^{16}$. Three potential correlations between sleep disorders and primary headache were described by Paiva ${ }^{17}$. First, headache may be the cause of sleep disorders, which has not been shown in previous studies, except in cases associated with serious psychiatric disorders and abuse of medications ${ }^{16,18}$. Second, sleep disturbances may cause headaches, as demonstrated in cases of sleep apnea ${ }^{19}$. Third, the likely association between these two conditions may indicate that they share a common intrinsic factor ${ }^{16}$.

Sahota et al. ${ }^{18}$ described a correlation between headaches and sleep disorders that could reflect an instability in serotonin levels in the two conditions. This would cause a significant change in sleep architecture, leading to a higher incidence of arousals, thereby interrupting the continuity of sleep. This potential dysfunction in the serotonergic system could be present at birth and result in sleep disorders during childhood and subsequent migraines during adolescence.

Among the sleep disorders, few studies have been able to specifically assess a history of STs in migraine patients. However, this association becomes important when analyzing the pathophysiologic mechanism of these two conditions. It was suggested that disturbances in the mechanisms which generate the slow-wave sleep and that the arousals are dependent on the serotonergic system. It is well known that the absolute amount and duration of the so-called slow-wave sleep, characterized by monomorphic waves of high voltage in the delta range, as well as the number of awakenings at this stage of sleep, are increased in children and adults with STs. This explains the behavioral changes observed in individuals and the development of research that led to the use of L-5-hydroxytryptophan (L-5-HTP), a precursor of serotonin, as a treatment for this condition ${ }^{20}$.

A dysfunction in the serotonergic system has also been implicated in the pathophysiologic mechanism of migraine headaches. Urine concentrations of 5-hydroxy acid, the main metabolite of serotonin, have been shown to be high in patients during an acute migraine attack. In addition, several pieces of evidence point to cortical hyperexcitability as a central disturbance in the pathophysiology of migraines, and abnormalities of calcium channels were reported as a potential mechanism because calcium influences the release of serotonin in the midbrain. Thus, dysfunction of these channels may prevent the release of serotonin and predispose patients to migraines by inhibiting the natural crisis abortion mechanisms ${ }^{21}$.

In the chronic migraine group, there was a predominance of women, which can be explained by the higher prevalence of migraines in women ${ }^{22}$. Subjects in the control group were significantly older than in the other groups, which may have decreased the possibility of an erroneous inclusion of younger children who might develop migraines later. Moreover, when comparing patients with and without STs within each group, there was no difference with respect to demographics such as age, sex, race or type of union between the parents, which ensured the homogeneity of our sample. In addition, there was no significant difference between groups regarding issues of quality of life.

Patients suffering from migraines had proportionally more reports of STs when compared to controls. A previous ST history was also higher in patients with chronic migraines than in patients with episodic migraines. This finding is in 
accordance with previous studies that have shown a strong association between headaches and specific sleep disorders $^{17}$, and in particular with studies that have shown an association between migraines and STs ${ }^{18,23}$.
Our study demonstrates a strong correlation between STs and migraines in adolescents, suggesting that a previous clinical picture compatible with STs in childhood increases the probability of developing migraines later in life.

\section{References}

1. Bigal ME, Lipton RB, Winner P, Reed ML, Diamond S, Stewart WF. Migraine in adolescents: association with socioeconomic status and family history. Neurology 2007;69:16-25.

2. Ando N, Fujimoto S, Ishikawa T, et al. Prevalence and features of migraine in Japanese junior high school students aged 12-15 yr. Brain Dev 2007;29:482-485.

3. Tietjen GE, Herial NA, Hardgrove J, Utley C, White L. Migraine comorbidity constellations. Headache 2007;47:857-865.

4. American Academy of Sleep Medicine. International classification of sleep disorders. 2nd ed. Westchester, Illinois, USA:American Academy of Sleep Medicine; 2005.

5. Nguyen BH, Perusse D, Paquet J, et al. Sleep terrors in children: a prospective study of twins. Pediatrics 2008;122:1164-1167.

6. DiMario FJ Jr., Emery ES 3rd. The natural history of night terrors. Clin Pediatr 1987;26:505-511.

7. Mason TB 2nd, Pack Al. Sleep terrors in childhood. J Pediatr 2005;147:388-392.

8. Owens JA, Millman RP, Spirito A. Sleep terrors in a 5-year-old girl. Arch Pediatr Adolesc Med 1999;153:309-312.

9. Barabas G, Ferrari M, Matthews WS. Childhood migraine and somnambulism. Neurology 1983;33:948-949.

10. Guilleminault C, Palombini L, Pelayo R, Chervin RD. Sleepwalking and sleep terrors in prepubertal children: what triggers them? Pediatrics 2003;111:17-25.

11. Isik U, Ersu RH, Ay P, t al. Prevalence of headache and its association with sleep disorders in children. Pediatr Neurol 2007;36:146-151.
12. Bruni O, Fabrizi P, Ottaviano S, Cortesi F, Giannotti F, Guidetti V. Prevalence of sleep disorders in childhood and adolescence with headache: a case-control study. Cephalalgia 1997;17:492-498.

13. Laberge L, Tremblay RE, Vitaro F, Montplaisir J. Development of parasomnias from childhood to early adolescence. Pediatrics 2000;106:67-74

14. Headache Classification Subcommittee of the International Headache Society. The International Classification of Headache Disorders: 2nd edition. Cephalalgia 2004;24:S9-S160.

15. Olesen J, Bousser MG, Diener HC, et al. New appendix criteria open for a broader concept of chronic migraine. Cephalalgia 2006;26:742-746.

16. Luc ME, Gupta A, Birnberg JM, Reddick D, Kohrman MH. Characterization of symptoms of sleep disorders in children with headache. Pediatr Neurology 2006;34:7-12.

17. Paiva T, Batista A, Martins P, Martins A. The relationship between headaches and sleep disturbances. Headache 1995;35:590-596.

18. Sahota PK, Dexter JD. Sleep and headache syndromes: a clinical review. Headache 1990;30:80-84.

19. Alberti A. Headache and sleep. Sleep Med Rev 2006;10:431-437.

20. Bruni O, Ferri R, Miano S, Verrillo E. L-5-Hydroxytryptophan treatment of sleep terrors in children. Eur J Pediatr 2004;163:402-407.

21. Couraud F, Seagar M. [Calcium channels and migraine]. Pathol Biol 2000;48:642-647.

22. Silberstein SD. Migraine. Lancet 2004;363:381-391.

23. Dexter JD. Headache and sleep. Headache 1988;28:671-672. 